\title{
La incertidumbre amorosa contemporánea Estrategias de los jóvenes
}

\author{
María Concepción Castrillo Bustamante \\ Universidad Complutense de Madrid, GRESCO-TRANSOC \\ mccastrillo@ucm.es
}

Recibido: 09-06-2015

Aceptado: 07-03-2016

\section{Resumen}

Este artículo explora las fuentes de incertidumbre en la experiencia contemporánea del amor y las estrategias que los jóvenes españoles ponen en práctica para afrontarla. Para ello, se utiliza el material empírico obtenido a través de la realización de 31 entrevistas en profundidad a adultos jóvenes entre 25 y 35 años de edad, residentes en Madrid. Su análisis ha permitido identificar una serie de estrategias que apuntan hacia la extensión de cierta "normatividad de la cautela" en la experiencia de los vínculos amorosos: a) La "disciplina emocional" para controlar la imagen que se otorga de los propios sentimientos, b) la concatenación de emparejamientos, c) la priorización del propio "yo" en las expectativas y d) la búsqueda de fórmulas alternativas al modelo de pareja monógama tradicional. Se analiza, además, cómo cada una de estas estrategias se hace plausible en función de determinados contextos y posiciones de clase y género.

Palabras clave: amor; pareja; incertidumbre; reglas del sentimiento.

\section{Uncertainty in Contemporary Love The Strategies of Young People}

\begin{abstract}
This article explores the sources of uncertainty in the contemporary experience of love and the strategies that young Spaniards put in place to address this uncertainty. To do so, we analyze 31 in-depth interviews conducted with young adults between 25 and 35 years old, living in Madrid (Spain). We have identified a number of strategies that point to caution as a normative influence on feelings: a) The "emotional discipline" to control the way our emotions appear to others b) the concatenation of partners, c) the subjective- prioritization of one's "self" and d) the search for an alternative to the traditional monogamous model of partnering. It also examines how different contexts and positions of class and gender make each of these strategies probable.
\end{abstract}

Key words: love; couple; uncertainty; feeling rules.

\section{Referencia normalizada}

Castrillo Bustamante M. C. (2016): "La incertidumbre amorosa contemoránea. Estrategias de los jóvenes", Politica y Sociedad, 53 (2), pp. 443-462.

Sumario: Introducción. 1. Fuentes de incertidumbre en la experiencia contemporánea del amor. 2. La nostalgia en los discursos sobre la pareja. 3. Estrategias frente a la incertidumbre amorosa. 4. Conclusiones. 5. Bibliografía. 


\section{Introducción}

En las últimas décadas se han producido importantes transformaciones en los modos en los que los afectos amorosos se experimentan. Estas transformaciones tienen lugar en un contexto de pluralización (relativa) de las formas de configuración de las parejas y las familias (Barañano y De la Paz, 1999; Beck y Beck-Gernsheim, 1998) y de erosión y redefinición de los roles tradicionales de género en el seno de ambas (García Selgas y Casado, 2010). A pesar de estos cambios, el amor y la formación de una pareja estable constituyen una de las aspiraciones centrales en la biografía de los jóvenes españoles (Meil, 2004). En momentos -como el presente- en los que diferentes dinámicas estructurales propician situaciones de inestabilidad y crisis en ámbitos igualmente fundamentales para sus vidas como el laboral y el económico, el amor, constituido culturalmente como promesa de felicidad (Jackson, 1993) puede experimentarse como elemento de arraigo y fuente importante de estabilidad subjetiva.

Los datos cuantitativos muestran que entre los 25 y los 34 años, algo más de un $80 \%$ de las personas en España forman algún tipo de pareja, y a partir de los 35 años casi el $85 \%$ de la población o bien ha sancionado su vínculo a través del matrimonio -civil o religioso- o bien convive (Ayuso y García, 2014: 57). No podemos, por lo tanto, hablar de la pérdida de importancia de la pareja como expectativa y como forma de organización biográfica en la sociedad española actual. Sin embargo, existen elementos en la experiencia contemporánea del amor que propician la incertidumbre también en este ámbito. Se han producido una serie de transformaciones en los procesos de formación de las parejas y en los modos de estar en las mismas que frecuentemente implican cambios importantes en las representaciones y expectativas sobre la propia vida amorosa hacia una mayor sensación de inseguridad. Si en ocasiones los afectos amorosos generan arraigo, en otros casos la falta de certezas en este terreno apuntala la sensación general de incertidumbre biográfica que la crisis económica y social está provocando entre amplios sectores de la juventud española.

Evidentemente, la inestabilidad en la experiencia amorosa no es vivida siempre -ni por todos y todas por igual- como problemática. Sin embargo, como veremos, existe una tendencia muy extendida entre los adultos jóvenes españoles a experimentar los usos amorosos contemporáneos con una marcada ambivalencia y cierta nostalgia de un pasado algo indefinido en el que las relaciones eran "más estables".

En este artículo nos centramos en el estudio de la incertidumbre amorosa y las estrategias que los jóvenes ponen en práctica para afrontarla, lo cual nos permitirá a su vez apuntar hacia determinados modos de experimentar los afectos amorosos que se relacionan con diferentes posiciones de género y clase social. Esta relación constituye una aproximación preliminar que, sin embargo, puede señalar vías de investigación sobre las que profundizar en el futuro.

Para conducir el análisis utilizamos el material cualitativo producido en el ámbito de una tesis doctoral sobre la experiencia del amor y la pareja de los adultos jóvenes en Madrid. Los objetivos de tal investigación, más amplios de los que se abordan en este artículo, se centraron en el análisis de diferentes dimensiones de la experiencia amorosa y de pareja (en los ámbitos práctico-emocional, de construcción del sentido y del deseo), en posibles cambios y continuidades al respecto y en los modos en que el 
género y la clase social sitúan la vivencia de los afectos. El trabajo de campo se llevó a cabo en los años 2012 y 2013 en la ciudad de Madrid y se basó en 31 entrevistas en profundidad a 15 hombres y 16 mujeres de entre 25 y 35 años de edad. Elegimos esta franja de edad porque nos interesan personas que han tenido experiencia práctica del emparejamiento, vivencias de amor y desamor, y un relato de todo ello ya alejado de la perspectiva de los primeros contactos con este ámbito de la experiencia. La elección de una etapa en cierto modo tardía de la juventud nos permite acceder a ciertas tensiones y contradicciones que pueden tener lugar en momentos en los que se producen diferentes equilibrios entre estabilidad $-\mathrm{o}$ el frecuente deseo por conseguirla- e incertidumbre.

La muestra se divide en cuatro trayectorias de clase social que eventualmente, y para los objetivos de este artículo, pueden clasificarse en dos grandes grupos en función de los estudios y profesión propios y del padre: a) licenciados-as o post-graduados universitarios procedentes de familias de clases medias con o sin capital cultural universitario y b) jóvenes sin estudios superiores -educación obligatoria o formación profesional- procedentes de familias de clases populares con niveles medios-bajos o bajos de capital económico y donde ni padre ni madre tienen estudios superiores. En las citas que utilizamos para ilustrar los argumentos de este artículo haremos referencia al primer grupo como "clases medias" y al segundo como "clases populares".

Para captar el sentido sociológico de los discursos y los relatos biográficos obtenidos nos proponemos un análisis que tiene en cuenta sus contextos de producción en un nivel doble: el de la interacción durante la entrevista y el más amplio que remite a las posiciones sociales y grupos de referencia de quienes hablan (Alonso, 1998).

\section{Fuentes de incertidumbre en la experiencia contemporánea del amor}

Un primer factor que propicia la incertidumbre amorosa contemporánea tiene que ver con lo que Illouz (2012: 73) entiende como la "desregulación de los encuentros románticos", tendencia enmarcada en la progresiva privatización de los modos en que se producen la elección amorosa y el emparejamiento en el mundo occidental. Para ilustrar esta idea, Illouz recurre a la comparación entre el cortejo victoriano, altamente ritualizado, y la configuración actual de los mercados del emparejamiento, en la que priman las decisiones individuales y en donde las conductas cada vez están menos codificadas y son por lo tanto menos previsibles. En su análisis del cortejo victoriano, Illouz explica cómo esta práctica se caracterizaba por su inserción en una red de relaciones más amplias con la familia y los grupos sociales de pertenencia, de modo que la formación de las parejas quedaba de algún modo supervisada de forma colectiva. Gracias a este control y a un conjunto de significados compartidos y conductas sancionadas, hombres y mujeres sabían lo que podían esperar del otro, de sí mismos y del proceso. Por supuesto, esta seguridad se asentaba en un arreglo patriarcal que establecía roles de género claramente definidos en torno a la autoridad masculina y la subordinación femenina.

En las sociedades modernas contemporáneas, por el contrario, el enamoramiento y la elección de pareja se convierten en ámbitos de la experiencia reservados al terreno de lo subjetivo. Esto no implica negar factores sociales que ayudan a modelar asimismo 
las subjetividades haciéndonos más o menos propensos a determinadas elecciones o preferencias. Lo que ocurre más bien es que el emparejamiento deja de estar sujeto a criterios objetivamente sancionados, del mismo modo en que deja de estar asentado en modelos de género perfectamente delimitados $-\mathrm{O}$ al menos, este asentamiento se vuelve más cuestionado y más incómodo-.

Este proceso de privatización se ve acompañado por el crecimiento de la importancia otorgada a la sexualidad como fuente de satisfacción y salud. El ámbito sexual se autonomiza y se convierte en una esfera separada de los afectos, con una relevancia social creciente apuntalada por disciplinas en auge, como la psicología. En España, la reducción del control normativo sobre las conductas en el terreno amoroso y sexual se inserta en el contexto de secularización de la sociedad, y especialmente en lo que Pérez-Agote (2012) entiende como "secularización individual", es decir, la progresiva pérdida de importancia de la religión en la vida de las personas. La "tercera oleada" de este proceso (2012: 139), que el autor sitúa a finales del s. XX, refleja la distancia cada vez mayor de las generaciones jóvenes con respecto a la Iglesia Católica y la religión, y la pérdida de importancia de los elementos religiosos en las representaciones sociales en torno a la familia, el matrimonio o las relaciones sexuales. Esta secularización, de la mano de diferentes movimientos sociales y políticos, -especialmente del feminismo- ha provocado cambios en los modelos de masculinidad y feminidad normativos y en los que hombres y mujeres ponen en práctica cotidianamente. Entre los hombres, el declive de la masculinidad del honor, representada en la España franquista por la figura del pater familias, supone cierta erosión del modelo patriarcal tradicional, pero implica a su vez que las conductas de los varones se plieguen en menor medida a la responsabilidad y la previsibilidad que constituían su fuente de autoridad (García García, 2010). Al mismo tiempo se produce un cambio significativo en el modelo hegemónico de feminidad, que se aleja de la imagen católica, tradicional, "decente" y sacrificada construida por el régimen franquista como prototipo de la española ideal, para dar paso a una pluralidad de modelos de feminidad posibles (Casado, 2002).

En este contexto, las prácticas ya no están marcadas por la consigna de la restricción y la condena del placer inmediato que marcaron los hábitos amorosos durante la dictadura, tal como mostró Carmen Martín Gaite (2007: 13-14). Entre los jóvenes españoles contemporáneos los encuentros sexuales esporádicos están legitimados y pasan a constituir en numerosas ocasiones el comienzo de un vínculo que puede estabilizarse o no con el tiempo. Tal como explica Illouz, las conductas, en menor medida controladas, codificadas y moralmente sancionadas, son más imprevisibles. Esto coloca a las personas, especialmente a las mujeres, en una situación ambivalente. Por una parte, es indudable que la relajación de los controles normativos y de la rigidez de los roles de género les permite hoy experimentar su propia vida amorosa y sexual con un grado mucho menor de restricciones y constreñimientos a su conducta. Pero esto no implica la desaparición automática de las desigualdades. En ocasiones, la conjunción de la legitimidad de los encuentros casuales y el anhelo de relaciones estables pueden propiciar no sólo un incremento de la incertidumbre, sino también la aparición de formas sutiles de dominación sobre las mujeres, cuando éstas adaptan sus 
expectativas y la propia imagen de sí mismas a los deseos del otro y a lo considerado "normal" en determinados contextos:

Y a lo mejor pasas esa noche con él y a la mañana siguiente ves como que la cosa ha cambiado un poco en su actitud y ya los siguientes días quedas a veces con él o tal, pero ves que él quiere quedar contigo para acostarse de vez en cuando o tal eh..., esas sí que he tenido unas cuantas de esas (...) Te hace sentir por una parte, por una parte en el sentido como utilizada o engañada o tal, pero también creo que hay una parte muy mía en el sentido de que a lo mejor, lo que te decía antes, yo le he idealizado demasiado rápido y he querido... Que tampoco soy una pesada de que yo les esté tal ¿no? Pero que a lo mejor intentas quedar otra vez y te empieza a dar largas ¿no? Y yo creo que tiene que ver un poco con eso, con que yo muchas veces a lo mejor idealizo a la persona sin conocerla. (Mujer, 31 años, clases medias)

El fragmento anterior ejemplifica la confusión después de varios encuentros que podrían desembocar en una relación o no hacerlo, la asimetría frecuente en la implicación emocional en el contexto de relaciones esporádicas entre hombres y mujeres jóvenes, y la incertidumbre con respecto a las expectativas e intenciones del otro. Además, pone de manifiesto otra característica típica del amor contemporáneo sobre la que argumenta Illouz (2012): la psicologización de todas las decisiones y desencuentros en el desarrollo de los vínculos. En el caso anterior, como vemos, la entrevistada atribuye la decepción por la actitud del otro y sus emociones al respecto a una característica "psíquica" propia, diagnosticando lo que entiende como una tendencia personal a la idealización antes de tiempo. Poniendo el acento en las características personales como "problema" se neutraliza la desigualdad de género que aquí se ejemplifica y que queda apuntada por la reiteración de esta tendencia en el trabajo de campo de esta investigación. En esta dinámica se pone de manifiesto que lejos de tal neutralidad, el género constituye un código que articula la interacción de forma cotidiana (Goffman, 1977), máxime en situaciones tan corporalmente marcadas como las relaciones afectivo-sexuales. Es decir, que en el contexto de ambivalencia contemporánea, las desigualdades se ven redefinidas más que desaparecer de la mano de la erosión del modelo tradicional de género.

Dentro de este proceso de psicologización del amor se enmarca otra de las fuentes de incertidumbre en su experiencia, que tiene que ver con el paso de un "régimen de performatividad de las emociones" a uno de "autenticidad" de las mismas (Illouz, 2012: 48). Esta transformación implica que el compromiso, la estabilidad de los vínculos y la satisfacción con la vida en pareja dependen hoy en mayor medida que nunca de si se siente amor "realmente", mientras que el mantenimiento de relaciones por cuestiones más allá de estos sentimientos pasa a considerarse una falta de honestidad con uno mismo. El régimen de performatividad implicaba que los sentimientos no surgieran en un momento inicial y revelador, sino que fuesen más bien el efecto -lento y previsiblede la puesta en práctica de una serie de ritos codificados y controlados socialmente. Por el contrario, en el régimen de autenticidad, el amor se autonomiza y se convierte en la causa tanto del establecimiento como del mantenimiento de tales vínculos. Esto no significa que otras consideraciones prácticas no formen parte -de manera más o menos 
reflexiva- de las decisiones en este terreno, sino que tanto las expectativas en cuanto a los propios sentimientos, como los conflictos, discusiones o rupturas en función de los mismos están más presentes en las parejas jóvenes contemporáneas, como ejemplifica el siguiente fragmento:

E: ¿Por qué motivo dejarías una relación?

S: Si no hubiese amor, si ya sintiese que es que no quiero estar con esa persona (...) Es que es muy irracional, de repente sientes que no hay amor". (Mujer, 30 años, clases medias)

\section{La nostalgia en los discursos sobre la pareja}

Los relatos de los y las jóvenes acerca de sus prácticas y decisiones en el terreno amoroso dejan entrever la extensión de este ethos de la autenticidad que implica la legitimidad asumida para mantener o abandonar las relaciones en función de los propios "dictados" sentimentales. Sin embargo, esto se combina con un discurso nostálgico muy frecuente que muestra la ambivalencia de su relación subjetiva con esta "ética postmoral" (Bawin Legros, 2004: 242), como ejemplifica el siguiente fragmento, perteneciente a la misma entrevista que el inmediatamente anterior:

Creo que también el amor entre la gente era más incondicional. Es decir, nos casamos y nos casamos para siempre, y superamos los problemas juntos, y no nos separamos en cuanto vienen mal dadas. Evidentemente, eso no se debe llevar al extremo, pero creo que ahora hemos perdido un poco eso. Cuando hay problemas: ¡Hasta luego, Lucas! Creo que... que falta un poco el compromiso a largo plazo. (Mujer, 30 años, clases medias)

Tal como manifiesta la contradicción en el discurso de esta joven, la aceptación del sentimiento como única guía de la conducta va acompañada muy a menudo de una pulsión tradicional manifestada en el anhelo nostálgico de relaciones "como las de antes", en las que se percibe un menor grado de incertidumbre y una mayor seguridad propiciada por una manera de entender el compromiso que no lo sujeta a revisión continua. A este respecto, podemos observar tendencias de género y clase interesantes. Entre las mujeres, este discurso nostálgico se ve matizado frecuentemente por el reconocimiento de la importancia de esta mayor autonomía en las decisiones como avance en igualdad:

Antiguamente las mujeres aguantaban carros y carretas y no creo que estuvieran enamoradas. Era por la sociedad que había y con que no podían valerse por sí mismas, no podían ni... ir a sacar dinero al banco, pues tú imagínate. Y hoy en día pues la gente aguanta lo que aguanta. (Mujer, 29 años, clases populares)

Significativamente, son los varones de clases populares los que presentan un discurso más crítico y desencantado con lo que evalúan en términos de fragilización de los 
vínculos amorosos contemporáneos, tal como queda ejemplificado en los siguientes fragmentos:

Y las relaciones que hay ahora no son las que había antiguamente. Porque antes, eso sí es ser una pareja y compromiso, lo que hay ahora es cachondeo, no compromiso (...) Ahora las relaciones son de gelatina comparadas con las que había antes. (Hombre, 26 años, clases populares)

La gente es que ya ve la relación de pareja como bf... pues es como un álbum de cromos yo creo, cuando se te acaban las pegatinas coges otro álbum de cromos (...) En plan de aquí te pillo aquí te mato, y está bien visto encima. (Hombre, 30 años, clases populares)

Esta posición vehemente al respecto, cargada de implicación afectiva ${ }^{1}$ con el tema, responde probablemente al hecho de que lo que se entiende como nuevo modelo amoroso constituye aquí una amenaza hacia la propia identidad. La familia nuclear basada en un vínculo estable y con una clara separación de roles entre los géneros constituyó para los hombres de generaciones anteriores con los que estos jóvenes han crecido como referentes la fuente principal de imagen de sí mismos, y su papel como "proveedores" de sus familias proporcionaba la definición hegemónica de la masculinidad, basada en la autoridad y el privilegio. Tal identidad se ve en peligro ante dinámicas sociales que puedan amenazar la perdurabilidad del vínculo en el que finalmente se apoyan, y esta amenaza es más acuciante -si bien no necesariamente consciente o reflexionada- para los hombres de clases populares, ya que ellos tienen negado en mayor medida el acceso al estatus y al valor social a través de otras fuentes, como pudiera ser una posición económica o profesional de prestigio.

En cualquier caso, lo que estos discursos muestran, con mayores o menores matices, es cierta incomodidad con el cambio percibido en torno a lo que Merton denomina las "duraciones esperadas socialmente" en el terreno amoroso. Con este concepto, Merton se refiere a ciertas "anticipaciones prescritas socialmente o estereotipadas de alguna $\mathrm{u}$ otra manera" (1992: 280-281) que, si bien no han de coincidir necesariamente con las duraciones reales, son consecuencia de la forma en que se producen las relaciones entre las personas, y al mismo tiempo, ejercen sus efectos sobre ellas. Es precisamente el efecto de estas anticipaciones lo que nos interesa en mayor medida aquí.

El análisis empírico de la experiencia del amor entre los jóvenes muestra multitud de referencias al miedo y a las formas contemporáneas de incertidumbre sobre las

${ }^{1}$ Usamos este término a partir de la interpretación que hace Martín Criado (1998) del concepto de implicación ("involvement") que para Goffman es "un proceso psicobiológico por el que el sujeto se vuelve, al menos en parte, no consciente de la dirección de sus emociones y su atención cognitiva" (1974: 346). Con este uso queremos señalar la relevancia que adquiere para estos entrevistados este punto concreto entre las cuestiones planteadas durante la entrevista, manifestada en la elevación del tono de voz y en la contundencia y seguridad en las propias afirmaciones. 
que se ha argumentado. Asimismo, ha puesto de manifiesto una serie de prácticas que se constituyen en estrategias desplegadas para lidiar con esa falta de certezas y con ese cambio en las duraciones esperadas en el terreno amoroso en un contexto en el que el amor no ha perdido su centralidad en las expectativas biográficas ni su poder como promesa de felicidad. Tales estrategias, cuyo análisis nos proponemos en lo que sigue, apuntan hacia la cautela como una "regla del sentimiento" (Hochschild, 1979) frecuentemente asumida.

\section{Estrategias frente a la incertidumbre amorosa}

Fijar como objetivo la comprensión de las estrategias de los y las jóvenes para lidiar con la incertidumbre, y en especial, con esa sensación de fragilización y contingencia de los vínculos, a la vez que experimentan mayoritariamente el anhelo de construir relaciones estables, no implica, tal como el uso de la noción de estrategias podría en principio sugerir, asumir una visión ligada a la teoría de la acción racional, que considera que los actores se mueven en función de cálculos sobre costes y beneficios. Más bien entendemos la estrategia de una forma cercana a la que plantea Bourdieu (1996).

Según este autor, el análisis sociológico debe abordar las razones de los agentes en sus situaciones cotidianas, ligadas a sus posiciones sociales, a su historia y a los contextos concretos en los que actúan, razones que son diferentes a la razón teórica que los investigadores tienden a asumir, y que implican un "sentido práctico", una serie de tendencias a actuar incorporadas que se ponen en práctica de manera "más o menos automática" (1996:70). Es decir, las estrategias no son necesariamente conscientes, lo cual no supone que sean necesariamente inconscientes. De la misma manera, como ya se ha señalado, no son racionales, es decir, no responden a una razón universal, sino a razones prácticas situadas: son razonables.

Existe, sin embargo, un aspecto de este sentido práctico que Bourdieu no ha atendido suficientemente. Nos referimos a su componente emocional. De alguna manera, la idea de "habitus" como sistema de disposiciones que produce ese sentido práctico lleva las emociones implícitas. Así lo sugieren, al menos, los afectos positivos y negativos que constituyen el gusto, ampliamente analizado por este autor (2012). El habitus genera tendencias a actuar, pero también a pensar y a evaluar, y esas evaluaciones no están exentas de implicación afectiva. Sin embargo, creemos que la obra de Bourdieu no lidia en profundidad con la dimensión emocional de las prácticas. Hochschild (2008) considera que esto es un problema común de la teoría sociológica, y se encarga además de enfatizar la falsedad de la dicotomía razón/emoción.

Partiendo de esta constatación, en el análisis de las estrategias que nos proponemos tendremos en cuenta que nos referimos a estrategias prácticas razonables y emocionales al mismo tiempo: tratan en gran medida de responder a emociones (el propio miedo a la pérdida y al sufrimiento amoroso), llevan las emociones implícitas, y en ocasiones, como veremos, también suponen la elaboración de las emociones propias buscando su ajuste a ciertas normatividades del sentimiento.

Se han identificado cuatro tipos de estrategias: las que tienen que ver con la "disciplina emocional" para contener la proyección de los propios sentimientos; la estrategia de 
los "emparejamientos solapados" ante la vivencia de la pareja como una necesidad y el miedo a la pérdida; la defensa del "centrarse en el yo" frente al amor como prioridad biográfica, y las "fórmulas alternativas" como manera de evitar decepciones ya experimentadas con el modelo tradicional de pareja estable y monógama. Si bien esta clasificación no es exhaustiva ni abarca todas las posibles prácticas de los jóvenes ante escenarios de incertidumbre, sí proporciona información relevante sobre situaciones sociales típicas que nos ayudan a avanzar en la comprensión de la vivencia de los vínculos afectivos en sus diferentes contextos en las sociedades contemporáneas. Con su análisis no pretendemos establecer determinaciones necesarias y automáticas entre diferentes posiciones de género-clase y ciertas estrategias prácticas, ni tampoco cubrir las prácticas amorosas de todo el espectro de posiciones sociales posibles. Más bien se trata de hacer comprensible el sentido de las estrategias que el trabajo de campo ha permitido identificar en los contextos específicos y situados que las hacen posibles para generar una interpretación sociológica de las mismas.

\subsection{La disciplina emocional}

Una primera estrategia que el trabajo empírico ha puesto de manifiesto tiene que ver con la desregulación de los mercados románticos y la ambivalencia de los primeros encuentros sexuales con la potencial pareja que ya hemos mencionado. Siguiendo a Hochschild (1979), la denominamos estrategia de la "disciplina emocional", porque se basa en el intento -consciente o no- por controlar la imagen acerca de las propias emociones y deseos amorosos que se proyecta ante los otros:

No, a mí me gustaría decirle lo que siento, porque sí, somos amigos, lo hemos hablao..., él de hecho me ha dicho: "Es que tenemos que acabar de hacer estas cosas, lo de liarnos, porque luego uno se va a enamorar, no sé qué", me dice: "Puedes ser tú o puedo ser yo" (...), y yo le digo: "Bueno", como quitándole importancia, pero yo en el fondo también pienso lo mismo. Yo me hago como la fuerte (...) Entonces yo algún día se lo tengo que decir. Tengo que hablar claramente, poner las cartas sobre la mesa y decirle: "Mira, esto es lo que siento". (Mujer, 27 años, clases populares)

Es como que veo todo mi futuro en él, ¿sabes? es como que... pa mí lo es todo y entonces, cualquier cosita que diga..., ahí, ya lo puede estropear todo ¿sabes? Entonces hay que ir despacio ¿sabes? Con pies de plomo ¿sabes? Para que las cosas no nos salgan mal (...). Yo ej que, me gustaría de verdad tenerle de frente y decirle: "Oye mira, siento esto por ti, dime sí o no porque yo ya no puedo vivir así, porque yo me estoy volviendo loca vamos". (Mujer, 25 años, clases populares)

Los anteriores fragmentos ilustran cómo frente a la falta de codificación de los primeros pasos en las relaciones amorosas, que genera imprevisibilidad acerca de las aspiraciones y el comportamiento del otro algunas mujeres sienten la necesidad de inhibir la expresión de los deseos y las intenciones propias, aunque esto les coloque en una situación incómoda. Tal como adelantábamos al comienzo de este artículo, las interacciones contemporáneas marcadas por la incertidumbre contextualizan en ocasiones dinámicas de desigualdad de género que sin embargo, no se identifican 
como tales, porque tienden a interpretarse en términos personales. En este caso, esa desigualdad se materializa en el trabajo emocional que realizan las mujeres tratando de adaptar la imagen sobre sus propios sentimientos a un ritmo que no suponga un peligro ante la potencial pareja. El trabajo emocional supone una forma de conformidad subjetiva con ciertas reglas del sentimiento, normas o convenciones sociales latentes y no explicitadas que establecen lo que es deseable sentir en diferentes situaciones, y cuál es el alcance, dirección y duración "apropiados" de diferentes emociones en determinados contextos (Hochschild, 1979: 564). En este caso, se trata de proyectar una auto-imagen que no rompa la regla implícita de no sentir más de la cuenta y antes de tiempo, evitando así que la otra persona -hombre- se asuste y abandone. Pero la configuración de estas reglas no es aquí neutral en términos de género, sino que parece responder más bien, como dejan entrever frecuentemente los relatos de los y las entrevistadas, a una adaptación femenina a los tiempos o las aspiraciones masculinas. En este contexto adquiere sentido que una de las jóvenes citadas, en sus propias palabras, se "haga la fuerte" delante de su pareja potencial para que él no crea que su relación tiene tanta importancia para ella, alejándose de esa manera del estereotipo de la mujer "desesperada" que aspira por encima de todo a una relación de pareja. O que otra de ellas vaya "con pies de plomo" ante el miedo a que la historia amorosa que está comenzando se estropee. En ocasiones, como muestra el relato de una de estas entrevistadas, esa disciplina a la hora de no mostrar demasiado los propios sentimientos tiene que ver con el "aprendizaje" a través de una experiencia pasada:

Lo estoy haciendo más despacio, porque si hubiera sido hace unos años, en cuanto nos liáramos tres veces le habría dicho... le habría expresao mis sentimientos (...) De: "Vamos a ser novios", lo que sea. Pero ahora no. Voy más calmada, sin precipitarme, si total, no sirve de nada. Y he aprendido que no me sirve de nada, ahora voy a hacer lo contrario. (Mujer, 27 años, clases populares)

El sentido de la contención emocional tal como queda aquí expresada se relaciona con la desilusión habitual que sucede a la ilusión romántica tras la constatación de la falta de intimidad o implicación de la pareja, dinámica que aparece frecuentemente en la experiencia afectiva de las mujeres (Langford, 1999). Pero lo que muestran los discursos de estas jóvenes es que esta contención ante el otro, lejos de implicar pasividad, responde a un trabajo activo con objetivos posiblemente no reflexionados pero muy presentes -objetivos que se hacen patentes en la entrevista sociológica, donde se genera una reflexividad hasta cierto punto "artificial"-. Más que ante un cálculo racional al respecto, estamos ante un aprendizaje pasado que ha generado cierto sentido práctico sobre "cómo estar" en las relaciones para, al fin y al cabo, adaptarse a los ritmos que se anticipa que son los deseables para el otro y así no perderlo. La desigualdad de género en esta dinámica se hace más patente cuando el miedo a la pérdida conlleva un tipo de inhibición en la expresión de las propias emociones por parte de las mujeres que se manifiesta en la auto-coacción a la hora de expresar el conflicto o el enfado:

A lo mejor pues se le cruzaba el cable y decía que se iba un mes a Asturias. Entonces pues cuando estás ahí teniendo una relación casi diaria, ya con tintes de 
comprometerse y de repente, cuando tú estás en el mejor momento y te dice que se va un mes a Asturias..., tú estás sabiendo que lo puede hacer, pero tienes ganas de decirle que es un puto egoísta porque no está contando contigo en ese momento ¿no?, o que te puedes sentir defraudada o lo que sea. Y esas cosas pues no me atrevía a hablarlas, y me las callaba. O a lo mejor me enteraba que se había follado a una tía. Obviamente no había..., no estábamos saliendo. Eso se puede hacer, pero una cosa es que se pueda hacer y otra cosa es que sea bonito o feo ¿no?, o que a mí no me genere una serie de emociones, que soy libre para comunicar, sobre todo si con esto pretendemos llegar a algo más y queremos que sea algo sincero. Pues no me atrevía a comunicarlo. (Mujer, 27 años, clases medias)

Tal como el anterior fragmento ejemplifica, esta reticencia autoimpuesta a mostrar la tristeza o el enfado ante las actitudes del otro se ve apuntalada cuando existe una cierta ambivalencia en la evaluación de la legitimidad del propio enfado o en la valoración sobre la aceptabilidad de las prácticas que lo han provocado, situación que se produce típicamente en las parejas en ciernes o en el contexto de los primeros encuentros en los que el vínculo no ha sido definido y por lo tanto, no está establecido claramente lo que "se puede hacer" o no. Como venimos argumentando, en esta situación incierta y "desregulada", las dinámicas de desigualdad de género pasan por la aceptación tácita de las mujeres de los límites que imponen -de forma no explícita- los hombres a través de sus ritmos y de sus niveles de implicación. Si el ajuste tradicional implicaba la adhesión por parte de las mujeres a un rol tradicional abnegado, y era en el plegarse a este rol donde se hacía manifiesta su desigualdad, en este "desajuste" contemporáneo, la abnegación, no asumida ya romo rol propio, toma en ocasiones formas más sutiles y se esconde bajo la deseabilidad de adoptar para una misma -y para el otro- la imagen de mujer moderna, que no se queja demasiado, que no pide demasiado, que no se implica demasiado o demasiado pronto, porque no lo necesita.

\subsection{Centrarse en el "yo"}

Cuando he tenido algo de trabajo de irme a otro sitio a estudiar o de tal cual, nunca he pensado que a la otra persona que se queda le puede... o sea no, igual lo veo porque pienso pues una relación pue' durar más, menos, o igual ésta va a durar para siempre, pero si yo hoy por hoy que estoy conociendo a alguien me ofrecen la oportunidad de irme a trabajar a Estados Unidos un año, pues me iría. Entonces no haría el sacrificio de, igual no mejorar en... Otros sacrificios pues igual sí que los haces, pero por ejemplo en el trabajo no. (Mujer, 29 años, clases medias.)

El anterior fragmento ilustra significativamente la adaptación de las expectativas biográficas a las duraciones esperadas socialmente sobre las que argumenta Merton (1992). Como ya hemos comentado, según este autor las duraciones percibidas, que no necesariamente coinciden con las reales, tienen efectos sobre la acción. En este caso, observamos al menos un efecto en el plano subjetivo de las expectativas: ya que hoy en día, según la entrevistada, no tenemos certeza sobre la resistencia de las relaciones de pareja, lo mejor es no sacrificar otros ámbitos de la vida que se consideran importantes. Es la que denominamos estrategia "centrada en el yo" pues se basa en la defensa -al 
menos, subjetivamente, ante uno mismo- de la prioridad de los propios intereses y de los propios "espacios" frente a las cuestiones amorosas y de pareja. Licenciada en física y programadora informática de profesión, la anterior entrevistada representa una trayectoria social ascendente de las clases medias españolas a través del capital escolar universitario, y en su discurso se pone de manifiesto la legitimidad de la prioridad de la profesión en estos sectores. Por eso defiende de forma explícita que nunca ha sacrificado sus estudios o su trabajo por una relación, y menos si ésta, en ciernes, no proporciona certezas. La entrevistada apela a un comportamiento normativo en las primeras fases de una relación para las mujeres de su posición social: como se trata de un periodo ambiguo, no es deseable "invertir" demasiado en algo que no se sabe si tendrá futuro, hipotecando otras decisiones biográficas importantes.

Beck y Beck-Gernsheim (1998) han argumentado que en las sociedades postindustriales existe una tendencia a la incorporación por parte de los actores de las exigencias de movilidad y flexibilidad del mercado de trabajo que afecta también a sus vidas privadas y sus vínculos amorosos, introduciendo en ellos un mayor grado de conflictividad y contradicciones. Sin embargo, ambos autores dan por hecho la idea de la carrera profesional, sin problematizar este concepto y sin atender al hecho de que ésta se hace presente y central entre aquéllos para los que el avance en el trabajo forma parte de las expectativas y en gran medida, de las ilusiones, es decir, entre sectores universitarios. Como muestra el caso anterior, para las mujeres con estudios superiores y perspectivas de ascenso profesional, la carrera es una fuente de identidad, estatus y auto-valoración de las que otras mujeres con trabajos menos cualificados están excluidas. Es decir, si la "independencia" plasmada en la priorización de la propia carrera se convierte en un "estándar emocional" (Illouz, 2014) o normal cultural extendida, no todos los grupos sociales tienen los mismos recursos para satisfacerla.

Por otra parte, el argumento de Beck y Beck-Gernsheim ha de ser atendido con precaución. La estrategia que aparece en este caso tiene que ver con una adaptación de las expectativas y de la propia presentación del yo durante la entrevista que no podemos saber si se traducirá en prácticas acordes, pero lo que sí deja ver su discurso es la legitimidad de cierta cautela en el terreno amoroso y de la priorización de los asuntos profesionales sobre los afectivos.

Esta defensa de la importancia de centrarse en uno mismo en lugar de en los asuntos amorosos, deseados pero percibidos como inciertos, no se manifiesta exclusivamente en la expresión del valor de la profesión:

He aprendido que hay que mantener espacios fuera de la pareja siempre, he aprendido que eso es fundamental (...) No perderte nunca porque las pasas putas luego. No perder nunca lo que eres, lo que te gusta, eh... no dejar de hacerlo, o sea, mantener tu espacio (...) Eso es importantísimo. Espacios de cada uno, salir con los amigos de cada uno... No hacerlo todo juntos, no hacerlo todo juntos. Porque luego cuando, si acaso lo dejáis, como es el caso, lo vas a tener mucho mejor. (Hombre, 31 años, clases medias) 
Tal como se desprende de este fragmento de discurso, el énfasis psicologista en el "yo" individual, sus "espacios", su enriquecimiento y su independencia, parecen responder frecuentemente a una defensa ante la experiencia de la decepción amorosa más que constituir una expresión de individualismo posmoderno generalizado. En cualquier caso, estas reivindicaciones del individuo apuntan a la existencia de una serie de estrategias ante la incertidumbre o el miedo a la pérdida que pasan por el refuerzo de la propia autonomía, estrategias que en los casos anteriores toman forma en un plano subjetivo. Sin embargo, esta tendencia también se manifiesta en el plano de las prácticas, y la investigación empírica muestra que, en ambos niveles, las referencias al yo autónomo se encuentran significativamente más presentes entre los hombres. El auto-refuerzo y la auto-referencia aparecen frecuentemente en los relatos de los varones jóvenes como modo de gestionar la experiencia de la ruptura y los momentos postrelación. En algunas ocasiones esta tendencia se materializa en la simple reivindicación de estar sin pareja como una situación necesaria y positiva:

No sé, ahora es mi momento de centrarme en mí. En mí, solamente. Y en el futuro... Sí, no sé, ser independiente. (Hombre, 26 años, clases populares).

En otras, ese centrarse en uno mismo no implica necesariamente una renuncia a las relaciones de pareja, sino un modo de estar en ellas caracterizado por la implicación ambivalente en el vínculo:

Y ahora, pues no me entrego. Puedo estar con una persona, estar a gusto o tal, disfrutar, incluso pues una relación medio larga pero sin entregarme al 100\%. Y antes era muy... era fiel, y ahora por ejemplo cuando he tenido relaciones de medio plazo y tal no he sido fiel, no es una cosa que me haya preocupao. (Hombre, 34 años, clases medias)

\subsection{Los emparejamientos solapados}

Frente a la protección de la individualidad como modo de refuerzo de la autonomía en el terreno de los afectos, existe otra estrategia que pasa, por el contrario, por la priorización de los vínculos amorosos: la concatenación o el solapamiento de emparejamientos frente a la posibilidad de la pérdida.

Bauman (2005) interpreta el crecimiento en la pauta de las monogamias sucesivas como una manifestación más de la "liquidez" de la segunda modernidad. Según su pesimista diagnóstico del amor contemporáneo, los individuos han perdido tanto la capacidad para establecer relaciones afectivas sólidas como el interés en ellas. La crisis del amor que vislumbra se materializa en una lógica mercantil en las relaciones, según la cual la propia satisfacción y los propios intereses se conviertan en el motor de los actos y en el centro de las biografías de los individuos modernos. Sin embargo, si analizamos empíricamente algunas de las prácticas en el terreno amoroso que, descontextualizadas, parecerían aproximarse más a este ethos líquido sobre el que argumenta Bauman, observamos que su sentido es más complejo. De hecho, la investigación empírica conducida pone de manifiesto que la estrategia consistente en concatenar o solapar emparejamientos se hace patente precisamente en aquellos contextos en los que el amor 
es en mayor medida vivido como una necesidad. Evidentemente, en un contexto de cierta ética post-moral y de legitimidad del ethos de la autenticidad sobre el que ya hemos argumentado, esta posibilidad puede tener otros sentidos, pero éste es especialmente relevante aquí porque pone de manifiesto una manera de relacionarse con los asuntos amorosos que los conecta directamente con la vulnerabilidad.

M: Quedé con este chico para ir al cine, con mi pareja.

E: Con la de ahora

M: Sí. Y... quedé para ir al cine sin ningún otro miramiento. Y ya pues... me empecé a sentir viva

E: Lo habías conocido por Internet,

M: Chateando

E: Mientras estabas con el otro con, que dices que el otro...

M: Sí, lo conocía de hace 6 meses por lo menos porque yo me metí en una página de... pues el "Badoo"

(...)

M: Y... a los 6 meses nos fuimos a vivir juntos. De conocernos y al año pues me quedé embarazada.

E: ¿Y tú cuando entrabas en el Badoo, tu idea era más ligar con chicos o encontrar pareja?

M: Yo no quería pareja, ¡yo qué coño voy a querer pareja! No jodas, yo quería estar ahí tol día liá

$\mathrm{E}: \mathrm{Y}$ entonces ¿Por qué crees que...?

M: Porque me llenó. Porque me... porque me llenó." (Mujer, 29 años, clases populares)

Para entender el sentido del rápido cambio de pareja que la entrevistada relata en este fragmento es necesario situar socialmente su experiencia amorosa. Tras una relación de quince años que incluye episodios de maltrato por parte de un hombre adicto a las drogas, esta joven, tal y como ella misma expresa, no quería nada más que relaciones esporádicas. Sin embargo, al año de conocer a su actual pareja -en un momento en el que aún mantenía la anterior- ya convivían y esperaban un hijo.

En el caso de las mujeres de clases populares, las modalidades de enriquecimiento del yo a las que algunos entrevistados-as aludían en el epígrafe anterior son más extrañas a sus estilos de vida. La centralidad que adquiere la pareja desde edades más tempranas en sus biografías hace que en muchas ocasiones, otros espacios de sociabilidad estén menos presentes, como sucede en el caso de esta misma entrevistada:

Luego ya me eché novio con trece años y mis amigas empezaron a ser los amigos de él. Entonces mis amigas las dejé un poco apartadas, y tengo una amiga desde que tenía nueve años, que sigo manteniéndola pero la veo poquito. No tengo muchas amigas la verdad.

Por otra parte, centrarse en las expectativas e ilusiones puestas en la carrera profesional es complicado cuando el trabajo se percibe como un medio instrumental para ganarse 
la vida y no como una fuente de realización personal, lo cual constituye la tendencia mayoritaria entre las clases populares (Bourdieu, 2012; Crespo et al., 1998). De este modo, es razonable que el sufrimiento por la pérdida amorosa se ataje con la implicación en un nuevo vínculo afectivo en un contexto en el que la formación de la pareja y la familia suponen el eje vertebrador del ideal de feminidad incorporado:

Yo quería tener hijos joven, no quería sobrepasar los 30 , que lo he conseguido, pero para mí ahora mismo ya es tener hijos demasiado mayor. Yo hubiera preferido tener hijos con 26 años, lo ideal 26 años (...) Siempre he querido tener mi casa y casarme y tener mis hijos y todo.

Tal como explica Kauffman (1993) entre los sectores con menores expectativas de movilidad social dentro de las clases populares -y especialmente entre las mujeres- el calendario de la unión no responde a la formación de la pareja progresiva típico de las clases medias contemporáneas, sino que es aún predominante la aspiración a un matrimonio precoz. Esto es así debido a que para ellas el matrimonio y la formación de una familia son aún la principal fuente de identidad social, que les otorga un lugar en el mundo, lugar además valorado, legítimo, y sancionado a través de una ceremonia codificada como es el rito matrimonial.

En algunas ocasiones, en este mismo contexto de centralidad biográfica de la pareja, la urgencia o necesidad con la que se vive su formación -expresada en la secuencia o solapamiento de los vínculos- se convierte en un modo de atajar otras vulnerabilidades:

Me agarré a él como un clavo ardiendo. Que dije, necesito... una salida. Tenía este chico al lao que sólo verle y estar con él pues ya eres feliz. Y de repente te quedas sin trabajo, te quedas sin casa, te quedas sin él, vuelves otra vez a todo el infierno que era antes. Antes tenías una ilusión, ahora ya... como que vacía, triste, no tienes esas ganas de vivir que tenías antes (...) Ahora estoy contigo pero si el día de mañana te vas, yo vuelvo a la misma mierda de siempre. Es como si viera en ellos una salida, que te lleve a otro mundo. Pero claro, sabes que si se acaba eso se acabó todo. (Mujer, 26 años, clases populares)

La narrativa amorosa romántica promete la trascendencia de lo cotidiano y en función de ello, es razonable que triunfe como fuente de sentido y como experiencia emocional muy intensa allí donde la precariedad de la vida convierte la cotidianidad en intolerable y donde, por lo tanto, el amor constituye una vía de escape frente a la realidad. Ése es el caso de la entrevistada anterior, con una trayectoria cercana a la exclusión social, una historia familiar marcada por el alcoholismo de su padre y una situación presente de precariedad económica. Esto no significa que la idealización amorosa no esté presente en otros contextos, sino que el sentido que toma en éste -donde el amor parece generar espontáneamente la felicidad: "Sólo verle y estar con él pues ya eres feliz"- tiene una importante conexión con la vulnerabilidad social. La "urgencia" de amor que parte de la vulnerabilidad propiciada por las condiciones de existencia apuntala a su vez tal vulnerabilidad cuando la priorización del vínculo amoroso se lleva al extremo, porque "si se acaba eso se acabó todo". En este sentido, la alusión a lo "lleno" y lo "vacío" 
en los relatos de estas dos últimas entrevistadas se hace especialmente significativa, porque remite al protagonismo que adquieren el amor y la pareja como fuente casi exclusiva de ilusión y de estabilidad biográfica y al hecho de que, en función de ello, se vivan como una necesidad.

\subsection{Búsqueda de fórmulas alternativas}

Existe otra serie de estrategias ante la incertidumbre y/o decepción amorosa pasada que se materializan en la búsqueda de maneras alternativas de organizar las relaciones de pareja:

No sé, después de la última relación escarmenté (...) dejé de confiar en el amor, ahora mismo estoy en una relación abierta, y mira que nunca lo he estado pero precisamente por eso porque ya no... (...) Me parecía (el amor) el único... tampoco es un absoluto ¿no? Pero el único ideal en el que merecía la pena creer (...) Que no exista un compromiso, que sólo haya pasión. (...) Yo me encantaría deshacerme de todo eso tradicional, para evitar sufrir y... y sólo haber pasión. (Hombre, 26 años, clases medias)

De la mano de la sensación de inseguridad por la ambivalencia en las relaciones presentes, otra situación habitual que aparece en los relatos de los y las jóvenes es la decepción tras una ruptura, que provoca cierta desconfianza hacia los futuros vínculos. En el fragmento anterior se ejemplifica la desilusión de un entrevistado tras comprobar que el "único ideal en el que merecía la pena creer", el amor, también se queda en el terreno de lo utópico. Si el amor es una de las fuentes de experiencia de lo sagrado y de cierta trasdencencia del mundo en las sociedades racionalizadas y secularizadas (Beck y Beck-Gernsheim, 1998; Illouz, 2009; Weber, 1972), aquí se pone de manifiesto una nueva vuelta de tuerca del desencanto que afecta también a la experiencia amorosa.

La decepción romántica provoca a menudo un diagnóstico pesimista sobre las relaciones de pareja, que, en ocasiones, como ya vimos, se materializa en un discurso muy presente entre los jóvenes sobre la fragilización de los vínculos y la incapacidad de su generación para el compromiso. Otras veces, como este caso ilustra, ese diagnóstico toma una forma menos conservadora para apuntar una crítica hacia la configuración tradicional de las relaciones, considerada una fuente de sufrimiento. En el contexto de esta crítica emerge la necesidad de alejarse de las fórmulas convencionales y probar un modo de estar en pareja consciente de su contingencia y donde el vínculo se deshaga de algunos de sus componentes más asumidos, como la exclusividad sexual.

En este caso se ejemplifica en cierta medida la tendencia señalada por Giddens (1995) sobre la reflexividad propia de las relaciones contemporáneas, según la cual la pareja es susceptible de convertirse en un proyecto creativo en el que las guías normativas tradicionales dan paso a criterios más individualizados y privatizados. Sin embargo, de nuevo, es necesario situar en su contexto social esta configuración de las prácticas en el terreno de la pareja. El trabajo empírico conducido muestra que la reflexividad y creatividad en la vivencia de los propios vínculos amorosos materializadas aquí en fórmulas alternativas al modelo monógamo y tradicional- más que constituir tendencias sociales generalizadas, se hacen en mayor medida plausibles en 
determinadas trayectorias biográficas en las que se conjuga capital cultural, politización y cierto estilo de vida crítico con lo establecido, como sucede en el caso del entrevistado anterior. Estos factores se convierten en recursos disponibles para esa construcción creativa de la identidad que Giddens entiende como un proyecto del yo. Como veíamos a propósito de la anterior estrategia, allí donde se dan disposiciones más tradicionales y donde el modelo de pareja hegemónico es central como expectativa biográfica, este tipo de proyectos innovadores y menos sujetos a las fórmulas convencionales son menos frecuentemente pensables.

\section{Conclusiones}

El análisis conducido en este trabajo nos permite, por una parte, cuestionar o matizar varias de las argumentaciones de las teorías de la individualización aplicadas al amor, y por otra, apuntar una reflexión sobre varios aspectos de la vivencia de género y clase social en los vínculos heterosexuales. En primer lugar, los arreglos cotidianos a través de los cuales los jóvenes lidian -en el plano subjetivo y práctico- con miedos, inseguridades y decepciones amorosas presentan una mayor complejidad de la que es posible pensar a través de la metáfora de la liquidez desarrollada por Bauman (2005). En un contexto de debilitamiento de las consideraciones morales como guías de la conducta y de redefinición de lo normativo en lo que se refiere a las identidades de género, se hacen posibles prácticas destradicionalizadas. Pero el sentido de las mismas, en numerosas ocasiones, responde más a la importancia de la pareja como expectativa biográfica y al miedo a la decepción amorosa que a un desapego genuino a la idea hegemónica de pareja como vínculo estable y monógamo. Más allá de esto, los argumentos que apuntan a la sustitución de los ideales y expectativas tradicionales por otras más centradas en el propio proyecto individualizado han tendido a asumir implícitamente una uniformidad social a este respecto que es problemática si atendemos a la investigación empírica. Como hemos argumentado, las tensiones entre las expectativas sobre la propia carrera profesional y las exigencias del vínculo amoroso (Beck y Beck-Gernsheim, 1998) se hacen patentes en contextos sociales en los que el trabajo se vive como una fuente de auto-valoración, identidad y reconocimiento social. Del mismo modo, la innovación y la creatividad en la construcción del proyecto de pareja (Giddens, 1995) es una tendencia en mayor medida plausible desde posiciones de cierto capital cultural y politización. Es decir, ambas tendencias corresponden más a los usos amorosos de sectores de las clases medias que a patrones universales.

Por otra parte, a pesar de que algunas de las formas más tradicionales de desigualdad de género en la pareja están viéndose erosionadas, ésta, como hemos argumentado, no desaparece de la interacción amorosa. La primera estrategia analizada, que hemos denominado estrategia de la "disciplina emocional" muestra que - de forma transversal a la clase social- existe una manera de encarnar la feminidad en los afectos por la que las mujeres tienden a adaptarse emocionalmente a los ritmos del otro para no resultar "molestas" ante la pareja o la potencial pareja, lo cual incluye, en ocasiones, inhibir la expresión del enfado o evitar la manifestación de conflictos. Si la comunicación implica reconocer al otro-a (Lasén y Casado, 2012: 7) las mujeres la evitan frecuentemente en 
los inicios de las relaciones como una forma de no mostrar excesivo reconocimiento hacia la potencial pareja, estrategia que paradójicamente parece ponerse en juego como modo de proteger el vínculo, evitando que una implicación excesiva rompa ciertas reglas de interacción implícitas - marcadas por códigos de género- por las que no es deseable exponerse demasiado. Esta tendencia a no ser demandantes en exceso se ha observado en otros trabajos empíricos (Casado, 2014; Jackson y Scott, 1997) y parece por lo tanto formar parte de ciertas disposiciones femeninas a encarnar los afectos en el contexto contemporáneo. Si bien esta desigualdad específica aparece en mujeres de diferentes posiciones de clase, hay otros aspectos que matizan esta uniformidad en la tendencia femenina a la protección y priorización de sus lazos amorosos. Tal como hemos argumentado, en situaciones de especial vulnerabilidad social el amor puede hacerse más central en la biografía, porque constituye una vía de escape ante otras precariedades. Es decir, si bien la desigualdad de género en el amor apunta a una tendencia estructural, ésta se actualiza de diferentes modos en distintos contextos. $\mathrm{Y}$ ante otras vulnerabilidades, la necesaria vulnerabilidad que genera la experiencia amorosa puede verse acrecentada.

Una posición típicamente masculina en la experiencia amorosa, que queda apuntada por el manejo de la incertidumbre por parte de los hombres, es la que se corresponde con la encarnación del "yo fortaleza", tendente a proteger su autonomía como estrategia defensiva en el terreno de las relaciones (Lasén y Casado, 2012: 7). Este patrón puede verse fomentado precisamente por el crecimiento de las inseguridades amorosas en los contextos contemporáneos. Las mujeres no quedan excluidas totalmente de esta norma cultural en que se ha constituido la "independencia emocional", sino que se acercan cada vez más a ella (Hochschild, 2008). Pero en ese desplazamiento, no todas cuentan con los mismos recursos. Los estilos de vida de las mujeres de clase media, entre las que los anhelos profesionales están muy presentes, son más propicios a este "centrarse en el yo" que los de las mujeres de clases populares, donde la pareja y la familia ocupan a menudo el centro de las expectativas biográficas. Los hombres de clases populares se sitúan en un territorio ambivalente al respecto. Si bien desde su posición de género - una vez erosionado el modelo de la masculinidad del honor al que se ha aludido- el refuerzo de la autonomía se hace frecuente como estrategia frente a la vulnerabilidad amorosa, el apego a un modelo tradicional menos incierto está muy presente en sus discursos. Desde este lugar, es razonable que la innovación que supone la estrategia de la búsqueda de fórmulas alternativas a los referentes hegemónicos sea poco frecuente en las expectativas. Por otra parte, la vivencia del género en este tipo de vínculos que implican el cuestionamiento consciente y reflexionado del modelo de pareja tradicional merece mayor investigación empírica.

\section{Bibliografía}

Alonso, L. E. (1998): La mirada cualitativa en sociología: una aproximación interpretativa. Madrid, Fundamentos.

Ayuso, L. y L. García (2014): Los españoles y la sexualidad en el siglo XXI, Madrid, CIS. 
Barañano, M. y J. De la Paz (1999): "Pluralización de los hogares y de las formas familiares. Hacia la familia post-tradicional", en S. González Ortega (coord.), Seguridad Social y Familia, Madrid, La Ley, pp. 1-54.

Bauman, Z. (2005): Amor líquido. Acerca de la fragilidad de los vínculos humanos, México, Fondo de Cultura Económica.

Bawin-Legros, B. (2004): "Intimacy and the new sentimental order", Current Sociology, 52 (2), pp. 241-250.

Beck, U. y E. Beck-Gernsheim (1998): El normal caos del amor. Barcelona, El Roure. Bourdieu, P. (1996): Cosas dichas, Barcelona, Gedisa.

Bourdieu, P. (2012): La distinción. Criterio y bases sociales del gusto, Madrid, Taurus.

Casado, E. (2002): "La construcción socio-cognitiva de las identidades de género de las mujeres españolas (1975-1995)" Tesis doctoral, Departamento de Sociología V, Universidad Complutense de Madrid.

Casado, E. (2014): “Tramas de género en la comunicación móvil en pareja", en A. Lasén y E. Casado (eds.) Meditaciones tecnológicas: Cuerpos, afectos, subjetividades, Madrid, CIS, pp. 55-68.

Crespo, E., J. C. Torregrosa, J. Bergère y J. L. A. Estramiana (1998): "Los significados del trabajo. Un análisis lexicográfico y discursivo", Sociología del Trabajo, 33, pp. 51-70.

García García, A. (2010): “Exponiendo hombría. Los circuitos de la hipermasculinidad en la configuración de prácticas sexistas entre varones jóvenes", Revista de Estudios de la Juventud 89, pp. 59-78.

García Selgas, F. y E. Casado (2010): Violencia en la pareja: género y vínculo, Madrid, Talasa.

Giddens, A. (1995): La transformación de la intimidad. Sexualidad, amor y erotismo en las sociedades moderna, Madrid, Cátedra.

Goffman, E. (1974): Frame Analysis. An essay on the organization of experience, Nueva York, Harper \& Row.

Goffman, E. (1977): “The Arrangement between the Sexes", Theory and Society, 4 (3), pp. 301-331.

Hochschild, A. (1979): "Emotion work, feeling rules and social structure", American Journal of Sociology, 85 (3), pp. 551-575.

Hochschild, A. (2008): La mercantilización de la vida intima. Apuntes de la casa y el trabajo, Madrid, Katz.

Illouz, E. (2009): El consumo de la utopia romántica. El amor y las contradicciones culturales del capitalismo, Madrid, Katz.

Illouz, E. (2012): Por qué duele el amor. Una explicación sociológica, Madrid, Katz.

Illouz, E. (2014): El futuro del alma. La creación de los estándares emocionale,. Barcelona, Katz-CCCB.

Jackson, S. (1993): "Even sociologists fall in love: An exploration in the sociology of the emotions", Sociology, 27 (2), pp. 201-220.

Jackson, S. y S. Scott (1997): "Gut Reactions to Matters of the Heart: Reflections on Rationality, Irrationality and Sexuality", Sociological Review, 45, pp. 551-575.

Kaufmann, J.C. (1993): Sociologie du couple. Paris, Presses Universitaires de France. 
Langford, W. (1999): Revolutions of the heart: Gender, power and the delusions of love, Londres, Routledge.

Lasén, A. y E. Casado (2012): "Mobile telephony and the remediation of couple intimacy", Feminist Media Studies 12(4), pp. 550-559. http://dx.doi.org/10.1080/14680777.2012.741871

Martín Gaite, C. (1996): Usos amorosos de la posguerra española. Barcelona, Anagrama.

Martín Criado, E. (1998): “Los decires y los haceres", Papers, 56, pp. 57-71.

Meil, G. (2004): "La pareja en el horizonte vital de las nuevas generaciones. Deseos y realidades", Revista de Estudios de la Juventud, 67, pp. 39-54.

Merton, R. K. (1992): "Las duraciones esperadas socialmente. Un estudio de caso sobre la formación de conceptos en Sociología", en R. Ramos (ed.), Tiempo y Sociedad, Madrid, CIS, pp. 275-306.

Pérez-Agote, A. (2012): Cambio religioso en España. Los avatares de la secularización, Madrid, Centro de Investigaciones Sociológicas

Weber, M. (1972): Ensayos de sociología contemporánea, Barcelona, Martínez Roca. 